\title{
EL PELIGROSO MADRID DE LAS ALELUYAS
}

\author{
Salvador GARCÍA CASTAÑEDA
}

The Ohio State University

\section{RESUMEN}

De Madrid y de las costumbres de sus habitantes a lo largo del siglo XIX se han ocupado numerosos autores tanto españoles como extranjeros; aquí me propongo estudiar la visión que ofrecen las aleluyas de esa ciudad y de esas costumbres, una visión propia de la literatura popular, paralela a la que ofrece la culta. Estas aleluyas sirven de ejemplo para mostrar la influencia de ambas literaturas entre sí; y a través de su visión esquemática y simplista las aleluyas difunden una moralización y una crítica social dirigidas a un público formado en su mayoría por las clases bajas.

Palabras clave: Aleluyas, Literatura de cordel, Costumbres, Madrid

\section{ABSTRACT}

We know about 19th century Madrid and its inhabitants, its customs and mores through the works of contemporary authors, both Spanish and foreign. In this essay I intend to study the people of Madrid and their customs as they are described in aleluyas, a sub-genre of popular literature that offers a perspective parallel to that of high culture. These aleluyas exemplify the mutual influence of both kinds of literature and, through their simplistic perspective they offer moralization and social criticism to a public mainly formed by the lower classes.

Key words: Broadsheets, customs and mores, Madrid

En el siglo XIX las ciudades eran el centro de la vida administrativa, artística y literaria y, como señala Edward Baker, hasta aquel siglo no se conocía en España ninguna idealización de la ciudad como hábitat (1991: 36). El Madrid decimonónico surgiría como protagonista por obra y gracia de Eugenio de Tapia, de Antonio Flores, de Mesonero Romanos y de Benito Pérez Galdós. 
El lector moderno que no esté familiarizado con la vida en las demás grandes ciudades de aquel tiempo como París o Londres, cuyos esplendores y miserias contaron Balzac y Dickens, se escandalizaría ante la carencia de respeto a las ordenanzas municipales de los madrileños, a la escasa presencia de la policía y a la insensibilidad de un público que se entretenía contemplando como un espectáculo más las ejecuciones en garrote vil.

Pero ya en 1832, en «Las costumbres de Madrid», en «Policía urbana» y después en las Memorias de un setentón, a vueltas con criticar las malas costumbres ciudadanas, destacaba Mesonero los cambios en las costumbres de los madrileños así como las mejoras urbanísticas de la ciudad. La Desamortización de Mendizábal en 1836 incrementó notablemente la actividad económica, y en el lugar ocupado por las iglesias, conventos y otras propiedades eclesiásticas desamortizadas se alzaron casas de nueva planta, se abrieron nuevas calles, plazas y jardines, y monumentos como el obelisco de la Fuente Castellana y el mausoleo del 2 de mayo. En Ayer, hoy y mañana, Antonio Flores pinta el Madrid de 1850 en pleno fervor de derribo y construcción, y destaca el impacto económico de la nueva publicidad impresa difundida a través de carteles y periódicos (Haidt, 2009: 299-318), y en una extensa nota a «Policía urbana» posterior a 1850, «El Curioso Parlante» se complacía en declarar cuánto había cambiado y mejorado la capital en aquellos años y enumeraba las grandes reformas de los corregidores Domingo María de Barrafón y del marqués de Pontejos (Mesonero Romanos, 1967: 182-183).

Otras manifestaciones del desarrollo de la vida burguesa serían el interés por el teatro y por la ópera, la creación de ateneos y otras asociaciones, y el extraordinario incremento en la publicación de libros, periódicos y semanarios de carácter diverso. Por su calidad destacan el Semanario Pintoresco Español (1836-1857), una publicación ilustrada de carácter nuevo en España, encaminada a recoger y estudiar nuestras costumbres, fundada por Mesonero Romanos, que tuvo larga vida, y El Laberinto (1843-1845), que dirigió Antonio Flores.

La obra del autor de las Escenas matritenses (1836-1842) y de Tipos y caracteres (1836-1842) nos ofrece una de las visiones más detalladas del Madrid de la primera mitad del siglo. La triple vertiente del costumbrismo -la sátira y crítica política de Larra, el pintoresquismo de Mesonero y el regionalismo de Estébanez Calderón- estarán presentes en Los españoles pintados por sí mismos, que comenzó a salir por entregas a principios de 1843, y en las demás colecciones de tipos, estudiadas por María Ángeles Ayala, que aparecieron más tarde. Contemporáneas suyas fueron aquellas obras que recogían artículos de costumbres así como las grandes novelas realistas y naturalistas y aquéllos y éstas tenían en común la descripción de la sociedad contemporánea; el interés 
de ambos se fija «en idénticos motivos y se produce un continuo trasvase de asuntos, personajes de ficción, ambientación y preocupaciones ideológicas del artículo a la novela y viceversa» (Ayala, 1993: 17-18).

Como es sabido, paralelamente a esta literatura para el consumo de las clases acomodadas estaba la «literatura de cordel» que proveía de relaciones, gozos, romances de ciego, almanaques y aleluyas a las clases populares. Las aleluyas tocaban una amplia variedad de temas, entre ellos, los relacionados con la vida y las costumbres de ciudades tan populosas como Madrid, Barcelona y Valencia, en las que además, hubo una floreciente industria de pliegos de cordel. Estas aleluyas y otros pliegos que tocan los mismos temas muestran procesiones, desfiles, solemnidades callejeras y otras manifestaciones del diario vivir como «El rastro en Madrid», «Funcions de Barcelona» o «El mercat de Valensia» ${ }^{1}$.

De Madrid y de las costumbres de sus habitantes a lo largo del siglo XIX, se han ocupado numerosos autores, tanto españoles como extranjeros; yo me propongo aquí estudiar la visión que ofrecen las aleluyas de esa ciudad y de esas costumbres una visión propia de la literatura popular paralela a la que ofrece la culta. A pesar de ser esquemática y simplista no carece de moralización ni de crítica, y revela mejor conocimiento de la burguesía y de las clases bajas que de las altas. No me refiero en esta ocasión concretamente a quienes habitan la Villa y Corte pues preparo otro trabajo sobre los personajes y los «tipos» (en el sentido costumbrista de la palabra), que pueblan estas aleluyas ${ }^{2}$.

1. Varey documenta un «teatro pintoresco mecánico» que incluyó varios tipos de vistas de diferentes ciudades (1995: 369). Las que aparecen con más frecuencia son las más conocidas, Madrid y en segundo lugar Barcelona y Valencia aunque en ocasiones hay vistas de otros lugares más o menos exóticos.

2. Mientras no se indique los contrario, las aleluyas mencionadas aquí proceden de la Colección de aleluyas del Centro Etnográfico y Fundación Joaquín Díaz, Urueña, Valladolid, y son las siguientes: «Los Españoles pintados por sí mismos» (Núm. 214). Madrid 1870. Despacho de Marés y Compañía, calle de Juanelo, Núm 19; «Las casas por dentro»; «Madrid pintoresco» (Núm. 33) Madrid. 1856. Se hallará en la plazuela de la Cebada, Núm. 36; «El Rastro en Madrid» (Núm. 33, N 133) Lit. Boronat, Madrid; «Percances de Madrid. (Núm. 85). Madrid: 1870; Despacho de Marés y Compañía, calle de Juanelo Núm. 19; «Escenas matritenses. Peligros y costumbres de Madrid» (Núm. 27). Madrid: Despacho: Librería y Casa Editorial Hernando (S.A.), Arenal, 11; «Tipos madrileños» (Núm. 153). Lit. Boronat. Madrid; «La romería de San Isidro» (Núm. 85) Madrid 1863. Imprenta de Marés y Compañía, plazuela de la Cebada, 13; «Costumbres de antaño y ogaño». Madrid 1866. Imprenta de Marés y compañía, calle de la Encomienda, 13, (Núm. 100); Costumbres españolas. (Núm. 84) Madrid, 1868. Imprenta de Marés y compañía, Plazuela de la Cebada, núm. 13; «Las calles de Madrid. Tipos que se ven en ellas a distintas horas» ([Imprenta de Marés y compañía], Venta al por mayor. Encomienda 13. Madrid; «Trabajos y miserias de la vida». Imprenta de Marés y compañía, plazuela de la Cebada, 13. Madrid, 1864. 
Según Mesonero, las casas antiguas de Madrid, anteriores a las reformas, eran sombrías, con balcones de gran vuelo y una enorme ala de tejado ( $« \mathrm{La}$ casa a la antigua», I, 1967: 189-192), por dentro están «reducidas a una o dos enormes piezas y muchos callejones interminables; son demasiado grandes, son oscuras por lo general a causa de su mala repartición y combinación de entradas, salidas, puertas y ventanas» («Las casas por dentro», I, 1967: 8286). Todo lo contrario eran las nuevas, edificios con engañosas apariencias de palacio, en las que, como escribe Larra, «la población de esta coronada villa, se apiña, se sobrepone y se aleja de Madrid, no por las puertas, sino por arriba [...] que tienen más balcones que ladrillos y más pisos que balcones»; cuyas escaleras «son cerbatanas, por donde pasa la persona como la culebra que se roza entre dos piedras para soltar su piel». Pero continúan distribuidas a la antigua: «sala, gabinete y alcoba pegada a cualquiera de estas dos piezas; y siempre en la misma cocina, donde se preparan los manjares, colocado inoportuna y puercamente el sitio más desaseado de la casa.» («Las casas nuevas», 1886: 291). La viñeta 'Los edificios» de la aleluya «Costumbres de antaño y ogaño» muestra un caserón a la antigua, con escudo en la fachada y un amplio portal y, en contraste, las casas del presente (la aleluya es de 1866), unas colmenas altas y estrechas de seis y siete pisos a ambos lados de la calle, que confirman la descripción que de ellas hizo Larra, y hacen comentar irónicamente al autor de la aleluya: «Bien dice quien ve este suelo, / que desde Madrid al cielo».

En los edificios modernos de las ciudades del siglo XIX, como en los del París de Haussman, los pisos bajos eran los más codiciados y los ocupaban los dueños o los inquilinos acomodados, y en los altos, vivían gente modesta y la servidumbre. Mesonero destacaba la suciedad del portal de las nuevas casas, las habitaciones enanas y el estrecho patio interior, y daba una distribución representativa de sus inquilinos:

Abajo vivían un sombrerero y un ebanista; un diestro de esgrima en el entresuelo; un empleado y un comerciante en los principales; un maestro de escuela y un sastre en los segundos; una ama de huéspedes, una modista y una planchadora en los terceros; un músico de regimiento, un grabador, un traductor de comedias y dos viudas ocupaban las guardillas, y hasta en un desvancillo que caía sobre éstas había encontrado su asiento un matemático, que llevaba publicadas varias observaciones sobre las principales alturas del globo. («Las casas por dentro», I, 1967: 82-86)

Encuentro gran semejanza, incluso en el título, entre esta descripción de Mesonero y el pliego «Las casas por dentro», que muestra el interior de una casa de vecindad de este género. La ausencia de fachada permite ver la distribución característica en cinco pisos y guardillas. A la derecha está la estrecha escalera por la que suben un caballero, y después una dama, y baja un aguador con 
la cuba al hombro. A nivel del suelo, a la izquierda hay una ebanistería; a la derecha, otro negocio que podría ser un obrador o un taller. Y en el primer piso izquierda, la sala con chimenea de una casa particular, en la mano derecha, un salón con dos caballeros practicando la esgrima. En el segundo, a la izquierda, se ve el despacho de una casa particular; y a la derecha, un salón de la misma. Ocupan el tercero izquierda, una sastrería; y la derecha, una escuela; el cuarto izquierdo muestra una habitación, y el derecho, un taller de modista, con maniquíes. Y ya bajo los tejados, se ven cuatro mansardas, las de los extremos con los techos inclinados; en la de la izquierda hay un hombre sentado leyendo, posiblemente un estudiante; en la del centro izquierda, otro de pie, en un cuarto con una cama y una mesa con un tintero y una pluma; en la del centro derecha, otro toca el violín frente a un atril; y en la de la derecha, un geógrafo, sin duda, está sentado ante un globo terráqueo. Estampa, la de estas mansardas, muy propia de la literatura del tiempo, y unos personajes, tipificables, como los sabios, los poetas, los músicos y los artistas muertos de hambre que malviven en esas alturas.

Otra aleluya, Trabajos y miserias de la vida, trae ecos del mundo de Balzac y de Galdós y de la novela social y folletinesca de Eugene Sue y de Ayguals de Izco. En la gran ciudad donde «Son boardillas elevadas / de los pobres las moradas» (9), conviven muchos de los que llegaron llenos de ilusiones a conquistar la capital como el pretendiente que termina durmiendo en un banco del Prado (29); un cesante muerto de hambre (11); Don Julián, que vende el gabán en el Rastro para comer (14); el que vestido de caballero, se pasea «sin un cuarto en el bolsillo» (18); el fracasado que se suicida (28) y el que muere en el hospital.

Al igual que otros contemporáneos, Mesonero destaca los palacios, monumentos y jardines que dan a Madrid rango de metrópoli. Para divulgar este protagonismo de Madrid, las 40 viñetas del pliego «Madrid pintoresco» reproducen vistas de los monumentos más destacados del de entonces. Y en la primera viñeta, un artista sentado en el campo está dibujando la ciudad, que se ve a lo lejos, y las restantes retratan monumentos como la puerta de Alcalá o la estatua ecuestre de Felipe IV, palacios como el Real o el de Buenavista, centros de estudio como el Colegio de San Carlos y el Observatorio Astronómico, además de iglesias, museos, jardines y fuentes.

El inevitable Mesonero alababa en 1835, «la espaciosidad y desahogo» de las calles de Madrid, «la regularidad bastante general de su alineación, la variada y caprichosa pintura de las fachadas de las casas y sus distintas formas y dimensiones» y cómo cuando el reloj de la iglesia del Buen Suceso había dado las seis, volvían a renacer la animación y el movimiento de las calles, 
interrumpidos durante la siesta. Los cafés estaban todavía oscuros y vacíos, los carruajes que llevaban a las damas de paseo no habían comenzado a circular, y se oían los pregones de los vendedores ambulantes. (I, «Paseo por las calles», Escenas matritenses, 1967: 217-221).

A esta breve estampa correspondería el pliego «Las calles de Madrid. Tipos que se ven en ellas a distintas horas» que carece de propósito moralizador pues estos tipos no aparecen aquí en función de sus buenas o malas costumbres sino formando parte del entramado urbano. Me permito comentarle aquí por su excepcional interés pues contribuye a retratar el ritmo de la vida diaria de la ciudad, hacia (a juzgar por la ropa de estos personajes) mediados de los años 60. El primero en recorrer las calles a las 4 de la mañana era el hombre que distribuía la leche de burra considerada de gran alimento para la gente enfermiza; una hora después aparecían las beatas, que llegaban a oír misa antes de que abrieran la iglesia. A las 6 salían a la compra las criadas y, de paso, a ver al novio, y a las 7 se ponía en acción la portera, a la que el autor del pliego llama «agenta [sic] de policía con poco sueldo». A las 8 iban a trabajar las modistas, piropeadas por mozos y viejos, y a las 12, volvían de trabajar, cansados y hambrientos, quienes empedraban las calles. A la 1 de la tarde se abrían ya los garitos de juego, y quienes disponían de tiempo usaban las horas de la tarde, las niñas para ir a jugar a los jardines, los tenorios para perseguir a las muchachas, y las damas aristocráticas para pasear por los jardines del Parque de Madrid, que es «el paseo que hoy prefiere la sociedad más elegante para lucir los caprichos de la moda». A los ruidos propios de la ciudad se unía la voz del ciego cantando «su obligado romance titulado Las Marías son muy frías y de puros celos rabian» ${ }^{3}$, y un vendedor ambulante de café, le ofrecía «a cuarto la taza». Propios de la noche eran personajes como el sereno, las «muchachas de paso ligero y bromas pesadas» que paseaban a las 11 de la noche por la Carrera de San Jerónimo, los pobres vergonzantes, algún cesante, los borrachos y los rateros que se aprovechaban de ellos para desvalijarlos.

3. Se refiere a aquellos pliegos con listas en verso de nombres de mujeres, hombres, ciudades u oficios en los que cada uno iba asociado con ciertas características o modo de ser, y con alabanzas y dicterios generalmente impuestos por la rima. Como en otras narraciones del género de cordel, los títulos revelan su carácter satírico, «Sátira jocosa», «Sátira burlesca», o de novedad, "Sátira nueva de la nueva guerra», «Nuevo relato». Así, «Las Marías son muy frías / y de puros celos rabian; / las Franciscas vocingleras, /perezosas las Tomasas», y los hombres son «Ingratos, falsos, arteros/ inconstantes, bailarines, / son Danieles, Valentines. / Victorianos y Valeros». El mismo juicio apriorístico aguardaba a los hijos e hijas de las diferentes provincias españolas, como revelan otras publicaciones semejantes, entre ellas las aleluyas. 
La atracción que siempre ha ejercido la Corte sobre los forasteros y los peligros a los que están expuestos tiene una larga trayectoria que se remonta al siglo XVII. En los casi tres siglos que van desde la aparición de la Guía y aviso de forasteros que vienen a la corte (1620) de Antonio Liñán y Verdugo hasta el Libro de Madrid y advertencias de forasteros (1892) de Manuel Ossorio y Bernard, ha visto la luz una considerable cantidad de obras con títulos como Los peligros de Madrid, de Baptista Remiro de Navarra (1646), Los engaños de Madrid y trampas de sus moradores, de Mariano Nifo (1742), o Madrid por adentro y el forastero instruido y desengañado (1784). El libro de Liñán y Verdugo se cita como germen del posterior desarrollo del costumbrismo, y tiene el objetivo concreto de prevenir al recién llegado a la ciudad de «la vida de farsa y engaño que llevaban en ella los que casi siempre por la astucia y rara vez por la fuerza hacían sus tributarios a los poco expertos recién llegados» («Prólogo», pág. XLI). Las demás obras citadas tienen el mismo propósito, y, como escribe María de los Ángeles Ayala, todas comparten una preocupación moralizante y didáctica de signo religioso que distingue a estos escritores de los costumbristas del XIX, a quienes preocupa una realidad de la que son testigos y que está a punto de desaparecer. Tales asechanzas pueden consistir en malas compañías, falsos amigos y fingidos amores, todas ocultas bajo engañosas apariencias y, al ponerlas en evidencia los autores de estas obras imparten una lección moral. De otra índole son los peligros que atentan contra la seguridad personal o la integridad física del desprevenido transeúnte, como robos, atropellos y otros accidentes callejeros. Algunos de estos peligros acechan también a los visitantes del Rastro, otro teatro de apariencias engañosas - «Esas que ves tan pirantes/ son patronas de estudiantes» (41) -, donde el forastero está a merced de los rateros y de las insolencias de los chiquillos

Dentro de la tradición del libro de Liñán y Verdugo hay diversas aleluyas que previenen a los incautos de las engañosas apariencias de la vida en la corte, y muestran los peligros físicos a que están expuestos quienes transitan por sus calles. Temas, sin duda bastante populares, a juzgar por las diversas ediciones de los pliegos que bajo el nombre de «Percances de Madrid», «Escenas matritenses», «Tipos madrileños», «El Rastro en Madrid» o «La romería de San Isidro» incluyen entre sus viñetas varias dedicadas a aquellos percances. Se diría que al hablar de la ciudad los autores de estas aleluyas consideran imprescindibles las advertencias o que, y esto parece lo más probable, recurren a asuntos conocidos para completar las 48 viñetas de la aleluya con un tema más amplio. Excepto en aquellas dedicadas exclusivamente a los «Percances de Madrid», tales viñetas suelen alternar con otras dedicadas a los tipos y las costumbres urbanas. En la primera de «Percances de Madrid», la Fama vuela 
sobre la ciudad, y avisa tocando la trompeta, usando una conocida forma hibrida propia de las aleluyas, «Oíd, lectores, oíd / los percances de Madrid», y las «Escenas matritenses» lleva el subtítulo «Peligros y costumbres de Madrid». En cambio, «Tipos madrileños», comienza en tono más sentencioso asegurando que «Hay en las grandes ciudades / inmensas calamidades» y en la segunda viñeta, al pie de una vista de Madrid, afirma que "Y sobre todo esta tierra / ¡Vaya unos tipos que encierra!».

El contraste entre el ser y el parecer de los humanos y la enorme desproporción que existe entre la realidad y las apariencias preocuparon siempre a los moralistas y a los críticos de la sociedad de su tiempo. Como es sabido, un tema literario frecuente es el del "quiero y no puedo», y achaque de la burguesía ha sido el tratar de igualarse con la aristocracia, de la clase media el emular a los burgueses acomodados, y de las clases bajas el confundirse con la media. Y se nos vienen a las mientes la miseria vergonzante de Frasquito Ponte, la cursilería de las Miau, el afán de figurar de Rosalía Bringas, los falsos aires de potentado de don Joaquín María del Pez, y las pretensiones sociales de tantos otros personajes novelescos, galdosianos o no, que pueblan nuestra narrativa decimonónica.

De manera simplista las aleluyas reflejan las mismas pretensiones y las mismas miserias: las cocineras parecen «damas altaneras», y otros viven a costa de su novia. En ocasiones, estos ejemplos de apariencias engañosas ocupan dos o más viñetas formando así un minúsculo relato: en «Percances de Madrid» un provinciano enamorado de una que cree ser señora, al visitar una casa la encuentra fregando el suelo (36 y 37); en otra ocasión la aleluya pinta a un caballero de «los que de milagro existen», como Ruperto, que "parece un duque» pero compra su ropa en el Rastro, y le vemos caminando por el Prado, el paseo de los elegantes, aunque malvive en una boardilla y tan solo puede comer "pan y cordilla» (38-41). El autor tutea a quien lee o a quien escucha cuando le previene de los falsos amigos que luego le venden («Percances de Madrid»), y de la seductora desconocida que resulta ser una «buscona taimada», o del «gancho» que le puede dejar en la miseria (19-20). Tanto «Percances de Madrid» («Y el engaño y la apariencia / son aquí ladina ciencia») como «Tipos madrileños» («47. Se confunde aquí el jumento / con el hombre de talento. / 48. Y Madrid a toda hora / es la caja de Pandora») coinciden en su visión pesimista de la vida ciudadana. De otro género son los peligros que atentan contra la integridad física de quienes transitan por la ciudad. La aleluya «Escenas matritenses», cuyo título evoca el del libro de Mesonero, lleva en su primera viñeta el subtítulo «Peligros y costumbres de Madrid», y comienza con la tradicional advertencia a los forasteros: «El que 
en Madrid no haya estado / o sus costumbres no advierta, / al paso que se divierta / ponga atención y cuidado». Y por falta de ambos los «aturdidos» y los «viejos» padecen varios percances, como la pareja de burgueses descalabrada con la cuba del aguador, o «el tonto» que mira «con embeleso» a una joven sin ver a un carnicero que le golpea con el cerdo muerto que lleva al hombro; la mayoría son víctimas inocentes del desconsiderado atropello por el caballo de unos panaderos, o por unas burras, y en «Percances de Madrid» del de un distraído arrollado por un coche de caballos. Si madrugas, «muy groseros / te ensucian los barrenderos», explota el gas del alumbrado, y es fácil caer en las profundas alcantarillas. Las calles están en obras o sirven para ejercer oficios e industrias, y transitar por ellas resulta arriesgado: los fragmentos de piedras que labra un cantero ciegan a un señor, los carboneros cierran una calle con la enorme pértiga con la que pesan el carbón, y los mozos que limpian el pozo negro ensucian a los transeúntes. Desde los pisos altos arrojan a la calle la suciedad nocturna al grito de «¡Agua va!», quienes limpian un tejado dejan caer peligrosos trozos de teja, un canalón roto empapa a los transeúntes, o les blanquea un chorro de cal llovido desde un andamio, y al pobre Don Hilarión (llamado así por exigencias de la rima), le hiere el tiesto que cae desde «un balcón». Para Lee Fontanella «Algunos de los temas en particular habrían podido servir de comentario satírico sobre gran parte de una Europa en trance de progreso decimonónico [...] a la localización matritense de los asuntos de los «Peligros» no se le debiera atribuir demasiada importancia, ni en casos en los que se aplicaba algún nombre propio perteneciente a la ciudad de Madrid [...] generalmente, los 'Peligros' se basan en situaciones no particulares a ninguna localidad concreta» (Fontanella, 1976: 72-73)

Otras de la «inmensas calamidades» que anuncian los «Tipos madrileños» son las asechanzas de busconas y meretrices, ganchos, tomadores del dos, rateros «más ligeros que los guardias», en «Las calles de Madrid. Tipos que se ven en ellas a distintas horas» aparecen tahúres y prostitutas, y en fin, «Petardistas y ladrones / hay en Madrid a montones»; en las «Escenas matritenses» estos últimos arrebatan la bandeja al pastelero, quitan la ropa a un señor, y otros despojan a quienes están presenciando una ejecución por garrote.

Estas aleluyas y estos grabados estuvieron de actualidad durante el reinado isabelino, los tiempos de la Gloriosa y los de la Restauración; algunas pintan una ciudad todavía sin alumbrado y con aires de poblachón, con muchas casas de un piso y con obras que interceptan el paso en las estrechas calles. Por el día y aun más de noche, el tránsito es inseguro tanto por la presencia de ladrones y busconas como por la escasa eficacia de la policía. Aunque pensamos en el Madrid de Larra, tan incómodo por la rudeza de las costumbres y 
el provincianismo de sus habitantes, este es el posterior a la Desamortización, y las obras que causan tantos estropicios podrían reflejar cambios y mejoras urbanas. Los ofendidos son siempre caballeros y señoras de la burguesía, unos ya maduros y de aspecto próspero, y otros jóvenes, elegantes y de finos modales. En cambio, los agresores pertenecen a las clases populares: barrenderos, albañiles, canteros, aguadores de montera o carboneros de sombrerón manchego, todos insensibles y brutales, que ejercen su oficio sin la menor consideración por quienes les rodean.

Moralización y advertencia, sin duda, la de estas aleluyas que relatan y pintan las desdichas y engaños propios de cualquier metrópolis y que no son exclusivos de Madrid. Tanto la literatura de cordel española como la de otros países (broadsheets, literature de colportage) revelan la fascinación que han ejercido siempre sobre el público los seres infernales, la violencia y el misterio. Las aleluyas estudiadas aquí exageran la violencia y multiplican los peligros ocasionados por la desconsideración y la indiferencia de los individuos de la clase trabajadora hacia los de la burguesía. Quienes las leían, aparte de los niños, pertenecían en su mayoría a las clases populares ciudadanas, y les regocijarían los ridículos apuros y las desgracias de elegantes damas y caballeros de levita. Y para entretener y divertir a sus lectores estas aleluyas adoptan con frecuencia un tono irónico y festivo ante las desdichas de gente infeliz y desgraciada como el Feo Cabezotas, Tomás el jorobado o el enano Don Crispín (García Castañeda, 2003: 103-109).

El estudio de las costumbres en estos pliegos presenta diversos enfoques pues mientras unos se limitan a enumerar las propias de la ciudad o del país, otros moralizan, critican o satirizan a sus compatriotas, y en ocasiones revelan las creencias políticas de sus autores. De ejemplo podría servir «Costumbres de antaño y ogaño» una aleluya de estructura poco tradicional pues consta de 24 viñetas dobles que contraponen escenas propias de la vida española en el presente con las un ayer que, a juzgar por la ropa y las costumbres de los personajes parecen las de los tiempos de Carlos IV, y que recuerdan las que recoge Antonio Flores (Ayer) en Ayer, hoy y mañana.

El autor o los autores de esta aleluya rechazan rotundamente las nuevas costumbres y pintan una España descreída, inmoral y sin principios, a pesar de que ésta de ogaño está más desarrollada, es más próspera, tiene costumbres más libres y, a pesar de sus denuestos, es mucho más divertida y dinámica. Estas viñetas y estos pareados añoran nostálgicamente las morigeradas costumbres del ayer: los niños ya no respetan a sus padres (y muestra a unos bebés fumando y con sombrero de copa), la juventud se ha independizado y los modestos estudiantes de antaño peroran y aspiran hoy a grandes puestos, 
los militares hacen rápidas carreras, los aristócratas que se honraban con la amistad de ponderados frailes frecuentan hoy a majos y toreros, y hasta los manolos hablan de política y las manolas se codean con marqueses. Frente a los entretenimientos, tan inocentes y escasos de antaño (hay que recordar que en la década de los 40 aumentaron visiblemente los espectáculos, las diversiones y las publicaciones periódicas), los bailes en el Madrid de hoy duran hasta altas horas de la noche, las parejas se enlazan bailando, los novios hablan a solas y sin testigos de vista, y las artistas muestran las piernas en el teatro. En esta galería de excesos no podía faltar la denuncia de un lujo escandaloso y de una vanidad manifiestos en vestidos y carruajes costosos, e incluso en las procesiones y en los entierros la espectacularidad ha suplantado la piedad religiosa. Curiosamente, de esta censura del presente se eximen la prensa que nos pone al día de lo que ocurre en el mundo, y el ferrocarril que ha convertido en viajes de recreo aquellas interminables y penosas jornadas. Y la viñeta muestra un camino señalado por las cruces que marcaban el asesinato de inocentes viajeros y por las cabezas de los malhechores expuestas en la picota, lo que expresaría elocuentemente la inseguridad de aquellas jornadas.

En cambio, «Costumbres españolas» revela una España muy diferente. Está fechada en 1870, poco después de la «Gloriosa» revolución septembrina y en su primera viñeta España, una matrona en pie, con gorro frigio, lanza y escudo, saluda victoriosamente, flanqueada por una cornucopia, la chimenea humeante de una fábrica y un barco, simbólicos del progreso. Y el pareado inicial expresa el sentido general de esta aleluya: «La fértil España encierra / cuanto bueno hay en la tierra».

El tono es optimista y las diversas escenas muestran que en España la vida transcurre con próspera normalidad. Pero, con excepción de siete viñetas (los bailes del bolero en Andalucía, la jota en Aragón, las seguidillas de la Mancha, los bailes de Galicia y de Asturias, "Corren en los pueblecillos / algunas veces novillos», un labrador cavando), las restantes se refieren a la vida ciudadana y, en algunos casos, concretamente a Madrid («el Prado», «la corte»). Son escenas protagonizadas por una clase burguesa de damas bien vestidas y de caballeros con chistera, que celebra bodas, baila, pasea por el Prado y va al teatro, asiste a procesiones y desfiles, frecuenta los cafés, juega a las cartas, y se divierte en Carnaval. Los pareados destacan el «lujo brillante» de la Corte, las «Aristócratas reuniones / [...] en lujosos salones» así como las «animadas verbenas / donde se olvidan las penas». Las clases populares, vestidas con ropas propias de la clase trabajadora, parecen estar contentas con su suerte «Con donaire las mujeres / desempeñan los quehaceres», «Los hombres son laboriosos, / honrados y generosos» - van a los toros y cortejan a la novia 
tocando la guitarra en la reja (el novio lleva catite, obviamente un préstamo de otra aleluya) mientras que los señoritos, elegantemente vestidos conversan con las suyas sentados en el banco de un parque. Menestrales y burgueses celebran la fiesta del patrón de la ciudad en la pradera de San Isidro, acuden a ver los fuegos artificiales, las riñas de gallos, las cucañas, los juegos de sortija, y la elevación de globos, pescan y cazan, pasean en barca, comen opíparamente, y todos esperan la lotería. Paradójicamente la visión positiva y carente de crítica de este país de Jauja que es la España próspera y feliz, concluye con la imagen de un labrador cavando - «Sufre del sol el rigor / en el campo el labrador»-y la vida transcurre como siempre: suum cuique.

Un tema popular entre los costumbristas ha sido el de la romería de San Isidro y a ella dedicó Mesonero dos artículos, «Mayo. San Isidro» (Mis ratos perdidos, I, 1967: 21-22) y «La romería de San Isidro» (Mis ratos perdidos, I, 1967: 21-22).), en los que alababa la «hermosa pradera», «donoso sitio»y la alegría de los madrileños. Su descripción en el último artículo, expresa el animado ambiente de la fiesta y describe lo que se vendía en los improvisados puestos ${ }^{4}$. En la misma línea de intenso sabor costumbrista es la aleluya de Marés, «La romería de San Isidro» (1863), que va describiendo lo que se vende en cada puesto y los pregones propios de cada mercancía, como «Silbatos con bellas flores / a cuarto y a dos, señores» o «Rosquilla de Fuen-Labrada / que se da muy bien pesada». Para ganarse la vida acuden también a la romería un volatinero y los ciegos de los romances, el que muestra el tutilimundi, el que canta habaneras y la gitana que dice la buena-ventura.

Reina la alegría entre la multitud que participa de este «festín encantador»: «airosas y bellas» muchachas son requebradas por jóvenes imberbes, y «Como hay tan buen humor / se baila que es un primor». Unos entran en la ermita, otros meriendan y brindan aunque los borrachos dan la nota cómica, uno predica inconsecuencias, y a otro le echan de un figón a empujones. Entre tanta gente alegre, «Un cesante desdichado / ante un puesto se ha parado», y a pesar de la vigilancia de la policía, no faltan incidencias como peleas entre soldados y paisanos, y entre maridos y amantes. Y así, entre las bromas y la alegría general, la romería acaba felizmente.

«Trajes y costumbres de Madrid» es una curiosa aleluya de factura bastante simplista y primitiva, que recuerda un tanto a las de principios de siglo

4. «Puestos de santos, de bollos y campanillas de barro, tiendas caprichosas y surtidas de bizcochos, dulces y golosinas, puestos de buñuelos, de pasas, higos y garbanzos tostados, roscones de pan duro y frasquetes de aguardiente, tortas y soldados de pasta flora, dulces de ramillete y bizcochos empapelados, las fondas más renombradas tenían comedores improvisados» («La romería de San Isidro», Mis ratos perdidos, I, 1967: 21-22). 
aunque el modo de vestir de los personajes podría ser de hacia 1830. En lugar de versos figura tan solo el título al pie de la viñeta y, como su nombre indica, en esta aleluya van entremezclados los tipos y las escenas. Entre los primeros, aparte de algunos populares como el manolo y la manola y otros propios de la clase media, los demás son de oficios. La mayoría aparecen en Los españoles pintados por sí mismos aun cuando los dibujos no están inspirados en ellos (suponiendo que Los españoles sean anteriores a esta aleluya).

Las costumbres han sido escogidas de manera un tanto caprichosa, probablemente para completar las cuarenta y ocho viñetas necesarias, pues bajo este nombre también incluye una pedrea de los chiquillos, un motín, un chaparrón, las Ferias, el Rastro, una vista de la Fuente Castellana y otra de la Puerta del Sol. Pero las verdaderas costumbres son tan madrileñas como la de recorrer las calles la víspera del día de Reyes con el gallego de la escalera al hombro ${ }^{5}$, la bendición de los animales el día de san Antón, los carnavales y el entierro de la sardina, la conmemoración del Dos de mayo, la verbena de san Antonio y la de san Juan y el día de san Isidro.

El título y los grabados de algunas de estas aleluyas muestran influencias más o menos directas de colecciones de tipos como «Los españoles pintados por sí mismos» y tanto los autores de «Percances de Madrid» como de «Escenas matritenses», cuyo título evoca el libro de Mesonero, conocerían sin duda los grabados de «Peligros de Madrid» que fue publicando el Semanario Pintoresco entre 1836 y 1857. Como es sabido, ni las imprentas ni los autores de aleluyas tenían reparos en copiarse unos a otros o en buscar inspiración en obras literarias o artísticas conocidas, y como ya advirtió Durán i Sampere los

5. «[...] hay en Madrid, en el pueblo más culto de España costumbres tan ridículas y chocarreras que harían poco favor a la aldea más miserable y atrasada. Una de las escenas grotescas que no ha podido destruir la Ilustración, es la que ofrecen en la llamada noche de Reyes. Vayan ustedes a la Puerta del Sol y verán lo que es bueno y barato: desde lejos se siente un gran ruido de cencerros y zambombas que parece que va a pasar una procesión de demonios, y lo que pasa es un gallego cargado con una enorme escalera, acompañado por una multitud de granujas que le van alumbrando con sendas hachas de viento. Otros le dan una música infernal de cencerros, y trayendo y llevando al inocente que lleva la carga de acá para allá y de allá para acá atraviesan la población doscientas veces en medio de las carcajadas y silbidos de la multitud.

Yo no creo que la preocupación llegue al extremo de que todos los que cargan con la escalera vayan de buena fe a esperar la venida de los Reyes Magos; pero algunos estoy convencido de que lo creen tan de veras, que cuando amanece el día seis sin haber visto a los Reyes, se llevan un chasco solemne; hay otros que saben lo que pasa, pero si les dan de cenar y un par de pesetas son capaces de cargar con la escalera haciendo a las mil maravillas el papel de tontos» (Juan Martínez Villergas, «Los Reyes», El Dómine Lucas, 1844: 76-77).

Anales, 24, 2012, pp. 11-27 
periodistas, los escritores y los artistas buscaron temas y asuntos en el estro popular (76).

Lee Fontanella estudió los veintiocho grabados de «Peligros de Madrid» que fue publicando el Semanario Pintoresco entre 1836 y 1857, obra de conocidos pintores e ilustradores de entonces y halló que existía una relación entre estos «peligros» gráficos con los del libro Los peligros de Madrid de Baptista Remiro de Navarra, de 1646. María del Pilar Palomo relacionó los mismos grabados del Semanario con el artículo de Mesonero Romanos, «España en Madrid», en el que hay diez tipos minuciosamente descritos en su atuendo y costumbres de provincianos en Madrid, los relacionó con los de los «gritos» ciudadanos propios de la iconografía costumbrista europea y llegó a la conclusión de que aunque parece que Alenza dibujó aquellos tipos basándose aparentemente en el texto de Mesonero, sucedía lo contrario pues algunos de estos dibujos habían aparecido ya en otros contextos en números anteriores del Semanario Pintoresco (Palomo, 1996: 245-246).

En su día publiqué un trabajo sobre la influencia de estas ilustraciones del Semanario sobre el pliego de aleluyas «Percances de Madrid» pues de los diez y ocho casos que recoge el pliego, catorce habían aparecido ya en aquella revista, y las viñetas de la aleluya son una copia de aquellos, aunque simplificada y de peor calidad (García Castañeda, 1996: 171-178). Últimamente, la lectura del artículo de Mesonero «Policía urbana», me reveló curiosas coincidencias entre su texto y los de las viñetas de «Percances de Madrid», lo que confirmaría que el autor de esta aleluya conocía, no sé hasta qué punto, la obra del «Curioso Parlante». En «Policía urbana», a vueltas con las alabanzas a Madrid, a sus adelantos y mejoras, Mesonero critica abiertamente las molestias y «peligros» de la ciudad en términos que reproducen de modo muy semejante los versos y las imágenes del mencionado pliego ${ }^{6}$.

6. ... iba a torcer una esquina, cuando me miré rodeado de una docena de ligeros jumentillos que, recién aliviados de la carga de los costales de yeso, y animados por la flexible vara del mancebo que los presidía montado en el último término del más provecto, no me dio lugar a defenderme en regla, sino grotescamente con manos y pies, recordando de paso al mozo con palabras harto duras la benéfica orden que les previene conducir su ganado sujeto a fila; pero aun estaba yo dirigiendo mi filípica, cuando blandiendo la vara sobre los lomos de los pollinos, formó una densísima nube de yeso y desapareció con ellos [...] Salvéme lo mejor que pude de aquellos peligros; pero fue para tropezar en otro, enredándome en una cuerda atada a un palo que había delante de una obra, y por pronto que quise salir sufrí gran parte de la lluvia de cascote arrojada desde el tejado; apartéme de allí y fui a dar cerca de una docena de picapedreros que estaban labrando las piedras para una obra, los cuales acertaron a asestarme un guijarro a un ojo, en términos que hube de permanecer tuerto por todo el día (Mesonero Romanos, 1967: 181-182). 
Como escribía Donald Shaw, los costumbristas «perseguían el objetivo de hacer ver al público lector que España era una nación habitada por un pueblo con características muy marcadas, sean éstas motivo de orgullo, de simple interés o incluso a veces de suave crítica» (Shaw, 1996: 300). Algo que, a mi parecer, hicieron también las aleluyas con su propósito de dar a conocer y difundir entre un amplio público en su mayoría de las clases populares las costumbres de antaño y de ogaño de su propio país concienciándole de su diversidad y estimulando su conocimiento mutuo.

Estas aleluyas dedicadas a Madrid mostraban a sus lectores unos modos de vivir y unos tipos que ellos reconocerían con facilidad. Daban un retrato convencional y simplista de la vida ciudadana española contemporánea y algunas evocaban afectuosamente la España nostálgica de un pasado todavía reciente pero ido sin remedio por imperativo del progreso. Para sus autores, los nuevos tiempos traían confusión de ideas, peligrosa mezcla de clases y falta de respeto a establecidas costumbres que hasta entonces fueron tenidas por sacrosantas, e incluso algunos de ellos llevaban el didacticismo propio del género a extremos exageradamente negativos. Otros, como los de «Costumbres españolas», fechada en 1868, pintan una España muy diferente, en este caso, sería la de los albores de la «Gloriosa» orientada al progreso y al futuro. Pero como parte del enfoque predominantemente didáctico y costumbrista propio

[...] los gritos de los vendedores, agudos y disonantes; el descoco de las naranjeras; las ropas nada limpias puestas a secar en balcones y ventanas; los tocadores al sol en calles no muy retiradas; el humo de las hachas que acompañaron al Santísimo Viático impreso a propósito en las paredes del portal; las rejas salientes que amenazan los hombros de los adultos y las cabezas de los chiquillos; las riñas de los aguadores en las fuentes por tomar vez para llenar; las carretadas de bueyes cargados de carbón; las interminables filas de mulas conductoras de paja; los inevitables serones de los panaderos ecuestres; los muchachos que venden candela y suele arrimarla al que no la solicita; los que salen en tropel de las aulas o convierten la calle en público anfiteatro imitando la corrida de toros; los fogosos caballos de la brillante carretela que se dirige al Prado; la eterna pesadez de los simones; la silenciosa embestida de los bombés facultativos y la vacilante dirección de los calesines. [...] Mi desgracia iba como siempre delante de mí; cuándo me hacía tropezar con una muralla provisional de cascotes apilados, procedentes de una obra, y colocados a tres cuartas de la pared, entre la cual dejaban un estrecho callejón apenas suficiente para el paso de una persona; cuándo me lanzaba de pies en un montón de cal recién apagada; ora me enredaba en una fila de basuras colocadas en medio del arroyo con ocho horas de anticipación al acto de recogerlas; ora me ponía delante ciertos avechuchos nocturnos, cuyo mal aspecto y repugnante desvergüenza ofenden al pudor y la moral pública; por aquí me salía al paso una vacilante tertulia arrojada de una taberna; por allá oía aproximarse el ruidoso tren encargado de aquella parte más sucia de la limpieza; huyendo de su olorífica influencia en el acto solemne de sonar las once, me acogía a la otra acera, a tiempo cabalmente de recibir el rocío con que una amable deidad alimentaba los tiestos de su balcón. (Mesonero Romanos, 1967: 182). 
de estos pliegos está presente la advertencia de que las engañosas apariencias apenas encubren males sociales como el oportunismo político, la mendicidad y la pobreza, la prostitución y el robo.

\section{BIBLIOGRAFÍA}

Ayala, María de los Ángeles, Las colecciones costumbristas (1870-1885). Servicio de Publicaciones de la Universidad de Alicante, 1993.

Ayala, María de los Ángeles, edición, estudio y notas de Eusebio Blasco, Madrid por dentro y por fuera Guía de forasteros incautos. Universidad de Alicante: Biblioteca Nueva, 2008.

BAKER, Edward, Materiales para escribir Madrid. Literatura y espacio urbano de Moratín a Galdós. Madrid: Siglo XXI de España Editores, 1991.

BozAl FeRnÁNDEZ, Laureano, La ilustración gráfica del XIX en España. Madrid: A. Corazón, 1979.

CARRo CARbajal, Eva Belén, Laura Mier et al.,eds., La literatura popular impresa en España y en la América colonial. Formas y temas, géneros, funciones, difusión, historia y teoría. Salamanca, 2006.

Correa Calderón, Evaristo, Costumbristas españoles, I. Madrid: Aguilar, 1964.

CRUZ CANO, Juan de la, Colección de trajes de España, tanto antiguos como modernos. Ed. facsímil. Prólogo de Valeriano Bozal. Fundación Universidad-Empresa, Turner, 1988.

Los españoles pintados por sí mismos. Madrid: Ignacio Boix, 1843-1844, 2 vols. Ed. facsímil, Madrid: Editorial Dossta, 1992; 2ª . ed., Madrid: Gaspar y Roig, editores, 1851. Ed. facsímil, Sevilla: Extramuros, 2008.

Flores, Antonio, Ayer, hoy y mañana, o la Fe, el Vapor y la Electricidad, Cuadros sociales de 1800, 1850 y 1899, dibujados a la pluma por... Madrid: Imprenta de D. José María Alonso, 1853.

FlorES, Antonio, La sociedad de 1850, Edición y prólogo de Jorge Campos, Madrid: Alianza Editorial, 1968.

Fontanella, Lee, «Peligros de Madrid», Poemas y ensayos para un homenaje. Madrid: Editorial Tecnos, 1976, pp.67-79.

GARCía CASTAÑEDA, Salvador, «El pintoresco mundo de la calle o las costumbres del día en aleluyas», en Romanticismo 6, Actas del VI Congreso, El costumbrismo romántico (Nápoles, 27-30 de Marzo de 1996), Roma: Bulzoni,1996, pp.171-178.

GARCía CASTAÑEDA, Salvador, «Town versus country: the depiction of northern labourers in Madrid in the eighteenth and nineteenth centuries. Galician Review, 3-4 (1999-2000), 19-33; «Aldeanos en la Corte: las gentes del Norte de España, vistas por los madrileños (siglos XVIII y XIX)», Aleluyas, Urueña, Valladolid: tf! Etnografía, 2002, 56-77. 
García Castañeda, Salvador, «Vanitas Vanitatis: Las Ferias de Madrid,» en Anales de Literatura Española, núm. 20 (2008), 219-240.

GARCía CASTAÑEDA, Salvador, «Don Perlimplín, Don Crispín y otras vidas de aleluya», Salina. Revista de Lletres, 17 (November 2003), 103-109.

HAIDT, Rebecca, «Flores en Babilonia, Los «gritos» de Madrid y el imaginario urbano hacia 1850», 313, Journal of Spanish Cultural Studies, vol 10, No. 3 (Sept2009), 299-318.

LARRA, Mariano José, Obras Completas. Barcelona: Montaner y Simón, 1886.

Los gritos de Madrid. Colección de setenta y dos grabados. Edición facsímil. Madrid: Ediciones Guillermo Blázquez, 1982. Con introducción «Pregones de ayer y de hoy» de Ramón Gómez de la Serna.

Mesonero Romanos, Ramón, Obras, I. (Ed. y estudio de Carlos Seco Serrano). Madrid: BAE, CXCIX, 1967.

Mesonero Romanos, Ramón, Memorias de un setentón (edición de José Escobar y Joaquín Álvarez Barrientos). Madrid: Castalia, 1994.

Palomo, María del Pilar, «Texto e imagen en el Semanario Pintoresco: Mesonero y Alenza», en Romanticismo 6, Actas del VI Congreso, El costumbrismo romántico (Nápoles, 27-30 de Marzo de 1996), Roma: Bulzoni, 1996, pp.239-247.

Remiro De NAvarra, Baptista, Los peligros de Madrid. Zaragoza: Pedro Lanaja, 1646. Ed. facsímil de José Esteban, Madrid: Clásicos el árbol, 1987.

Rodríguez, Antonio, Colección General de los trajes que en la actualidad se usan en España. Principiada en el año 1801. Madrid: Librería de Castillo, 1801; Madrid: Ayuntamiento de Madrid, 1989.

Rubio CRemades, Enrique, Periodismo y literatura: Ramón de Mesonero Romanos y El Semanario Pintoresco Español, Alicante: Institut de Cultura 'Juan Gil Albert', 1995.

SHAW, Donald L., «La pintura... festiva, satírica y moral de las costumbres populares», en Romanticismo 6, Actas del VI Congreso, El costumbrismo romántico (Nápoles, 27-30 de Marzo de 1996), Roma: Bulzoni, 1996, pp. 299-305.

VAREY, J. E., Cartelera de los títeres y otras diversiones populares de Madrid: 1581840. Estudio y documentos. Madrid: Editorial Támesis S.L., 1995.

Fecha de recepción: 15-1-2012

Fecha de aceptación: 30-5-2012 